\title{
The Mayo conservative hip: complication analysis and management of the first 41 cases performed at a University level 1 department
}

Jörg Arnholdt ${ }^{1 *}$, Fabian Gilbert ${ }^{1,2}$, Marc Blank ${ }^{1}$, Jannis Papazoglou' ${ }^{1}$, Maximilian Rudert ${ }^{1}$, Ulrich Nöth ${ }^{1,3}$ and Andre F. Steinert ${ }^{1,4}$

\begin{abstract}
Background: To prevent bone loss in hip arthroplasty, several short stem systems have been developed, including the Mayo conservative hip system. While there is a plethora of data confirming inherent advantages of these systems, only little is known about potential complications, especially when surgeons start to use these systems.

Methods: In this study, we present a retrospective analysis of the patients' outcome, complications and the complication management of the first 41 Mayo conservative hips performed in 37 patients. For this reason, functional scores, radiographic analyses, peri- and postoperative complications were assessed at an average follow-up of 35 months.

Results: The overall HHS improved from 61.2 pre-operatively to 85.6 post-operatively. The German Extra Short Musculoskeletal Function Assessment Questionnaire (XSFMA-D) improved from 30.3 pre-operatively to 12.2 postoperatively. The most common complication was an intraoperative non-displaced fracture of the proximal femur observed in 5 cases (12.1\%). Diabetes, higher BMl and older ages were shown to be risk factors for these intra-operative periprosthetic fractures $(p<0.01)$. Radiographic analysis revealed a good offset reconstruction in all cases.
\end{abstract}

Conclusion: In our series, a high complication rate with $12.1 \%$ of non-displaced proximal femoral fractures was observed using the Mayo conservative hip. This may be attributed to the flat learning curve of the system or the inherent patient characteristics of the presented cohort.

Keywords: Total hip arthroplasty, Short hip stem, Mayo stem, Minimal invasive surgery

\section{Background}

Total hip arthroplasty (THA) is one of the most effective procedures in orthopaedic surgery. It provides pain relief and restores function as well as mobility. However, the optimal management of young individuals with osteoarthritis (OA) of the hip is still the subject of scientific controversy $[1,2]$. The principle of minimally invasive hip surgery (MIS) includes soft-tissue sparing techniques and conservation of autochthonous bone stock. It has been demonstrated that minimally invasive surgical approaches to the hip, e.g. the minimally-invasive direct

\footnotetext{
* Correspondence: j-arnholdt.klh@uni-wuerzburg.de

'Department of Orthopaedic Surgery, König-Ludwig-Haus,

Julius-Maximilians-University, Brettreichstr. 11, 97074 Würzburg, Germany

Full list of author information is available at the end of the article
}

anterior approach, might be able to reduce postoperative pain levels, decrease the intake of pain medication and shorten hospitalisation [3]. Soft-tissue preservation and conservation of authochthonous bone stock remains a major challenge in THA.

A steadily increasing number of young patients undergo total hip arthroplasty as quality of life standards in Western societies have increased during the last century while patients demand a great deal of their mobility even at higher ages $[1,2]$. Younger individuals are more likely in need of revision surgery with adequate femoral bone stock being essential for satisfactory results following revision arthroplasty. Resurfacing implants have shown acceptable short- and midterm results compared to conventional designs but higher complication 
rates such as fractures of the femoral neck and generation of metal ions that can be detected systemically $[4,5]$. Short stem systems offer the opportunity to combine MIS approaches with a bone conserving technology.

In 1985, Morrey et al. [2] introduced a $60 \mathrm{~mm}$ short, double tapered titanium alloy stem with metaphyseal four point fixation, termed the Mayo conservative hip (Zimmer International Inc., Warsaw, Indiana, USA). The Mayo conservative hip is a bone conserving femoral implant, which preserves bone stock at the neck and calcar femoris junction for later revision surgery [6-10]. Although there are several different conservative implants available, only few mid-term results have so far been published [11] and there is only little known about the problems surgeons face when introducing this system into their clinical practise. Therefore, the aim of this study was to evaluate the mid-term outcomes of the first patients treated with the Mayo conservative hip in our University Level 1 department.

\section{Methods}

\section{Study design}

This retrospective cohort study was performed at the Department of Orthopaedic Surgery, University of Wuerzburg, Germany and approved by the local institutional review board (IRB) of the University of Wuerzburg (Nr: 2016020501).

\section{Setting and participants}

Forty-one THAs using the mayo conservative hip were performed between April 2007 and May 2009 in 37 patients (16 women and $21 \mathrm{men})$. All patients were treated at the Department of Orthopaedic Surgery, University of Wuerzburg, Germany. The mean follow up period was 35 (range 9 - 45) months. The mean age at the time of the surgical intervention was 46.3 (range 16 - 63) years. The indications for THA were primary OA (12 cases, 29.2\%), or secondary OA due to developmental dysplasia of the hip (18 cases, 43.9\%), femoral head necrosis (6 cases, $14.6 \%)$, slippage of femoral epiphysis (4 cases, 9.8\%) and M. Perthes (1 case, 2.4\%).

Patients with previous operations at the pelvis or proximal femur (e. g. osteotomies, fracture fixation), morbid obesity, metabolic bone disorders and meta-epiphyseal dysplasias were excluded.

\section{Surgical approach}

In 29 cases the transgluteal standard lateral approach was used (Bauer), and in 12 patients the minimallyinvasive direct anterior approach (DAA). The surgical techniques used have been described previously by our group [12-15].

\section{Functional assessment}

Functional assessment was performed using the Harris Hip Score (HHS) and the German Extra Short Musculoskeletal Function Assessment Questionnaire (XSFMA-D). All peri- and postoperative complications were recorded. The scores were assessed before and after an average of 35 months following surgery. The XCMFA-D [16], a score based on the Short Musculoskeletal Function Assessment Questionnaire (SMFA), was used to evaluate musculoskeletal function from a patient's perspective [17]. The XSMFA-D is a 16-item version for routine assessment of functional capacity in patients with orthopaedic disorders. It analyses functional deficits and impairments due to inflammatory, degenerative and injury related causes [17].

\section{Radiographic analysis}

Radiographic analyses were performed using standing anterior-posterior (AP) radiographs of the pelvis and lateral radiographs of the proximal femur pre-operatively, postoperatively and during follow-up. All data were collected in a blinded fashion and random order. The lateral offset was measured between the lateral wall of the Koehler's tear drop and the medial point of the trochanter minor, while the vertical offset (=leg length) was measured from the highest point of the trochanter major to the lowest point of the os ischium (Fig. 1).

Stem alignment was measured on postoperative radiographs and classified into three groups: Varus alignment $\left(\mathrm{CCD}\right.$ angle $<120^{\circ}$ ), neutral alignment (CCD angle $120^{\circ}$ $140^{\circ}$ ) and valgus alignment (CCD angle $>140^{\circ}$ ) (Fig. 2).

The CCD angle was defined pre-operatively as the angle between the shaft axis and the femoral neck, and postoperatively between the shaft axis and the neck of the prosthesis (Fig. 1). The post-operative radiographs were also examined for radiolucency lines, osteolysis or increased density in the periprosthetic zones described by Gruen [10].

\section{Statistics}

Values were given as means, range and SD. We used the software SAS (Version 9.2, SAS Inst. Inc. Cary NC, USA) for all statistical analyses. Chi square analysis was used to compare differences between patients with or without risk factors (BMI, diabetes mellitus, approach). A $p$ value of $<0.05$ was considered significant.

\section{Results}

\section{Patient characteristics}

In five cases an intraoperative non-displaced proximal femoral fracture in the cortex was observed. In four of these patients a lateral approach was used, and one case an anterior approach. Patients with non-displaced proximal femoral fractures exhibited a significantly increased body mass index $(27.9 \pm 1.9$ versus (vs) $23.6 \pm 3.6$; $p<.01)$ and they were significantly older $(62.1 \pm 8.1$ years 


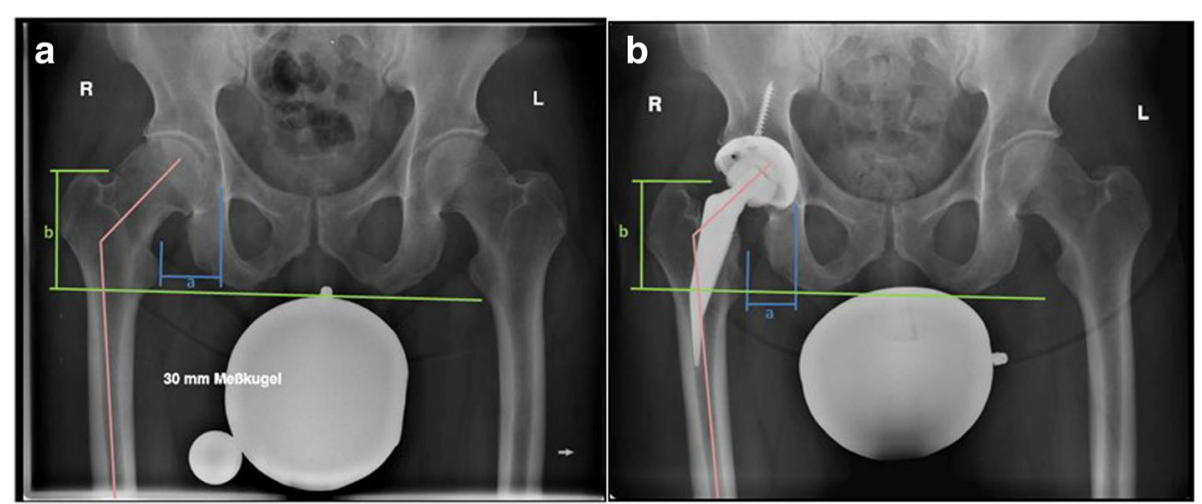

Fig. 1 Measurement of lateral offset from the lateral wall of the Koehler's tear drop of the pelvis and the medial point of the trochanter minor (see measurement a within Fig. 1a and b). The leg length (=vertical offset) was measured from the highest point of the trochanter major of the femur to the lowest point of os ischium of the pelvis (see measurement $\mathbf{b}$ within Fig. 1a and b). The centrum-collum-diaphyseal-angle (see pink line within Fig. 1a and b) was defined preoperatively as the angle between the shaft axis and the femoral neck, and postoperatively the angle between the shaft axis and the neck of the prosthesis

vs $49.5 \pm 8.3$ years; $p<.01)$ when compared to patients without fractures. Furthermore, the prevalence of diabetes mellitus was significantly higher $(p=.001)$ in the patient group with proximal femoral fractures. The usage of a standard lateral approach was not associated with a higher rate of non-displaced proximal femoral fractures when compared to the minimally-invasive anterior approach $(p=.063)$ (Table 1).

\section{Patient reported outcome and complications}

The HHS increased from $61.2( \pm 7.1)$ preoperatively to $85.9( \pm 6.4)$ after 35 months, with a range 65 to 91.5 .
The XSFMA decreased from $30.2( \pm 5.2)$ preoperatively to 12.2 ( \pm 4.3$)$ postoperatively. Complications included intraoperative non-displaced proximal femoral fractures (5 cases, 12.1\%, Fig. 3), aseptic loosening ( 2 cases, $4.9 \%$ ), acute late onset infection (1 case, $2.4 \%$ ), insufficient gluteus medius and minimus muscle-function (1 case, $2.4 \%$ ) and 1 delayed healing ( 1 case, $2.4 \%$ ). Implant survival was $95.2 \%$ after a mean of 35 months.

In the patient cohort treated with the lateral approach 8 complications were observed, while in the group with the anterior approach 2 complications occured (Table 2). One acute late onset infection 13 months after
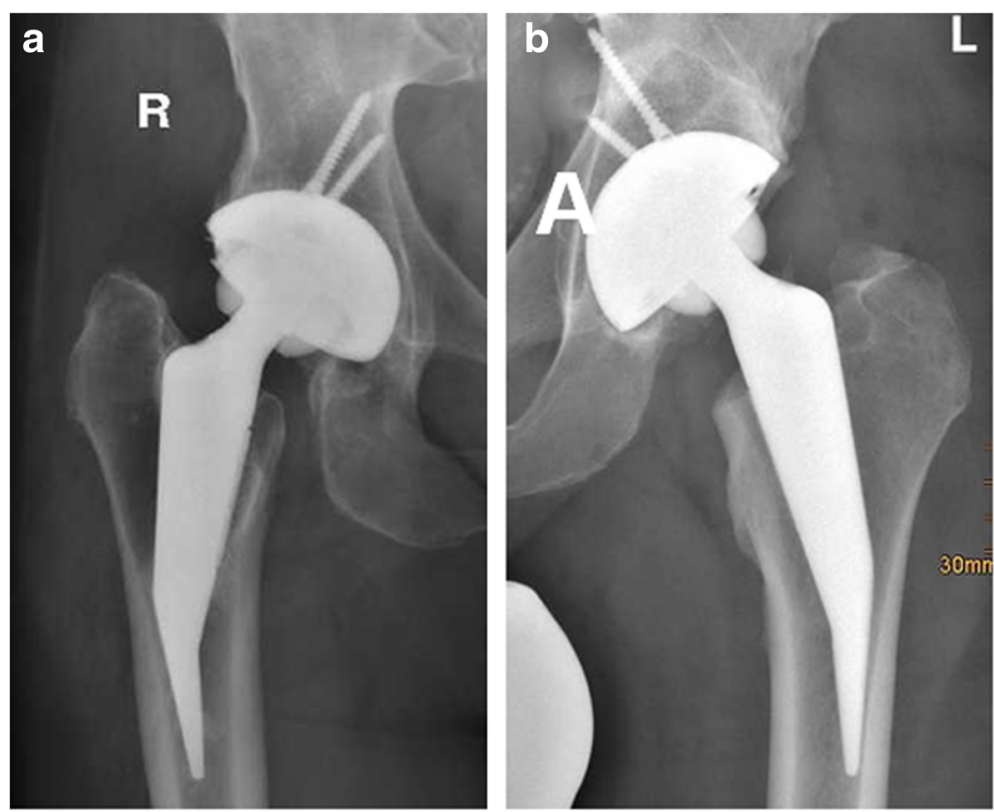

Fig. 2 Varus and valgus- alignement of the stem 
Table 1 Description of the cohort, and comparison between patients characteristics and patients with an intraoperative nondisplaced proximal femoral fracture in cortex

\begin{tabular}{llll}
\hline Characteristics & All Patients & $\begin{array}{l}\text { Intraoperative non- } \\
\text { displaced proximal } \\
\text { femoral fracture (Type-IA, } \\
\text { Vancouver Classification) }\end{array}$ & p value \\
\hline Age (in years) & $49.5 \pm 8.3$ & $62.1 \pm 8.1$ & $<.01$ \\
$\begin{array}{l}\text { Diabetes } \\
\text { Body mass }\end{array}$ & $10 / 37$ & $4 / 5$ & $=.001$ \\
$\begin{array}{l}\text { index (kg/m }{ }^{2} \text { ) } \\
\text { Approach (Bauer) }\end{array}$ & $23.6 \pm 3.6$ & $27.9 \pm 1.9$ & $<.01$ \\
$\begin{array}{l}\text { Developmental } \\
\text { dysplasia of the hip }\end{array}$ & $18 / 41$ & $4 / 5$ & $=.063$ \\
\hline
\end{tabular}

implantation was treated with exchange of the mobile parts in a one-step procedure.

Furthermore, two exchanges of the mayo short stem to a standard taper stem were necessary; One due to aseptic loosening after 13 months, and one due to postoperative stem sintering 13 days following surgery. An intraoperative non-displaced proximal femoral fracture in the cortex was observed in 4 cases in the group with the lateral approach and one case in the group with the anterior approach. Patients with proximal femur fractures were all intraoperative treated with a cerclage to secure the fracture (Fig. 4). Postoperatively, these patients were were limited to non weight bearing for 3 or 6 weeks, and after this $20 \mathrm{~kg}$ partial weight bearing before transition to full weight bearing. The occurence of proximal femur fractures did not reach any level of significance related to the performed approach.

\section{Radiographic analysis}

Radiographic analysis revealed signs of linear radiolucencies in 23 cases in zones 1, 3 and 5 of Gruen (Fig. 5) with the implant reliably fixed.

The CCD angle changed from $134.7^{\circ} \pm 6.4^{\circ}$ preoperatively to $132.8^{\circ} \pm 16.9^{\circ}$ postoperatively (Table 3 ). Neutral alignment was observed in 20 (48.7\%) hips, varus alignment in $9(21.9 \%)$ and valgus alignment in $12(29.2 \%)$ hips.

The lateral offset increased from $43.1 \pm 7.0 \mathrm{~mm}$ preoperatively to $46.2 \pm 16.5 \mathrm{~mm}$ postoperatively (Fig. 6, Table 3). A correlation between stem alignment and the appearance of periprosthetic fractures was not observed.

Leg length (=vertical offset) was changed on average by $4.3 \pm 12.8 \mathrm{~mm}$ (Fig. 7 , Table 3 ).

\section{Discussion}

The mayo conservative hip is a cementless implant with intertrochanteric fixation and preservation of bone stock at the femoral neck and calcar region. Compared to conventionally designed long-stemmed implants, the overall bone resorption over time in these regions is decreased $[5,18]$.

Preservation of bone stock in younger patients requiring hip replacement is essential since those patients will most likely experience at least one implant revision during their remaining lifetime [1-3]. In our study, HHS improved from 61.2 to 85.6. This can be regarded as a good result (the score is reported as 90-100 for excellent results, $80-90$ being good, $70-79$ fair, $60-69$ poor, and below 60 a failed result) [1, 2, 6]. In a retrospective study, Morrey et al. reported long term results of 159 patients with a mean follow up of 6.2 years.

The survivorship of the Mayo stem was 98.2 after 5 and 10 years. These results are in agreement with the results described by Falez et al. [6], who reported a survivorship of $97.5 \%$ after a mean follow up of 4.7 years (range, 1-7 years) a complication rate of $4.3 \%$. In our study, implant survivorship was $95.2 \%$ at the 35 months follow-up. This is in line with data for cementless implants provided by the Australian national joint replacement registry [19], describing implant survival rates for patients younger than 65 years of $96-97 \%$.

In our study, the Harris-hip-score (HHS) improved from 66.2 to 85.6. The major intra-operative complication was the occurrence of a non-displaced proximal
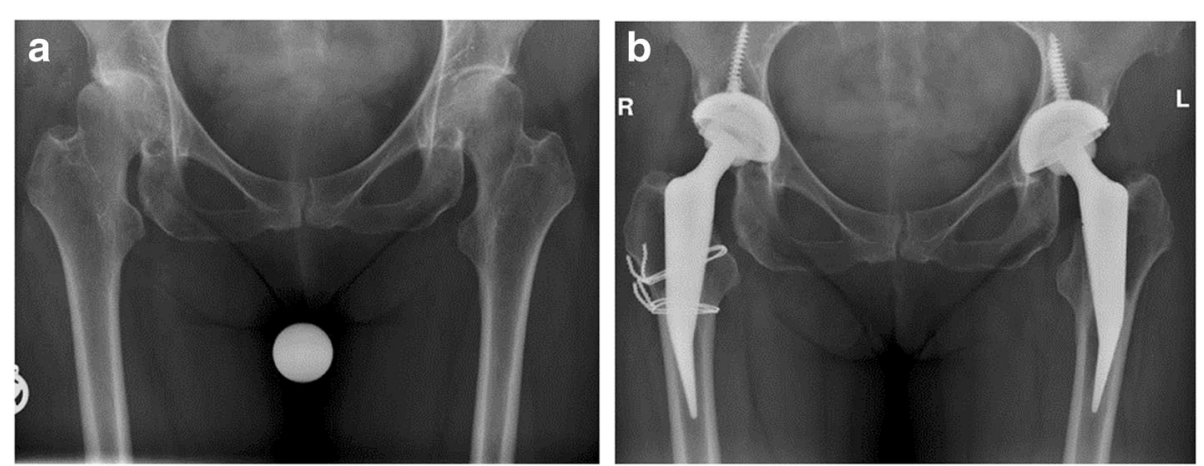

Fig. 3 a Radiographs of a 49 year old patient with developmental dysplasia of the hip on both sides (b) Postoperative view after implantation of a Mayo conservative hip and a Harris Galante II cup (Zimmer). An undisplaced proximal femoral fracture occurred intraoperatively on the right side and was secured with 2 cerclage wires. A significant increased densitiy can be seen in zone 3 
Table 2 Complications related to the surgical approach

\begin{tabular}{lll}
\hline Complications & $\begin{array}{l}\text { Lateral approach } \\
\text { (Bauer) }\end{array}$ & $\begin{array}{l}\text { Anterior approach } \\
\text { (DAA) }\end{array}$ \\
\hline acute late onset infection & 1 & \\
$\begin{array}{l}\text { aseptic loosening } \\
\text { delayed wound healing }\end{array}$ & 1 & 1 \\
$\begin{array}{l}\text { insufficiency glutei muscle } \\
\text { intraoperative non-displaced }\end{array}$ & 1 & 1 \\
$\begin{array}{l}\text { proximal femoral fracture } \\
\text { postoperative stem } \\
\text { sintering }\end{array}$ & 1 & \\
\hline
\end{tabular}

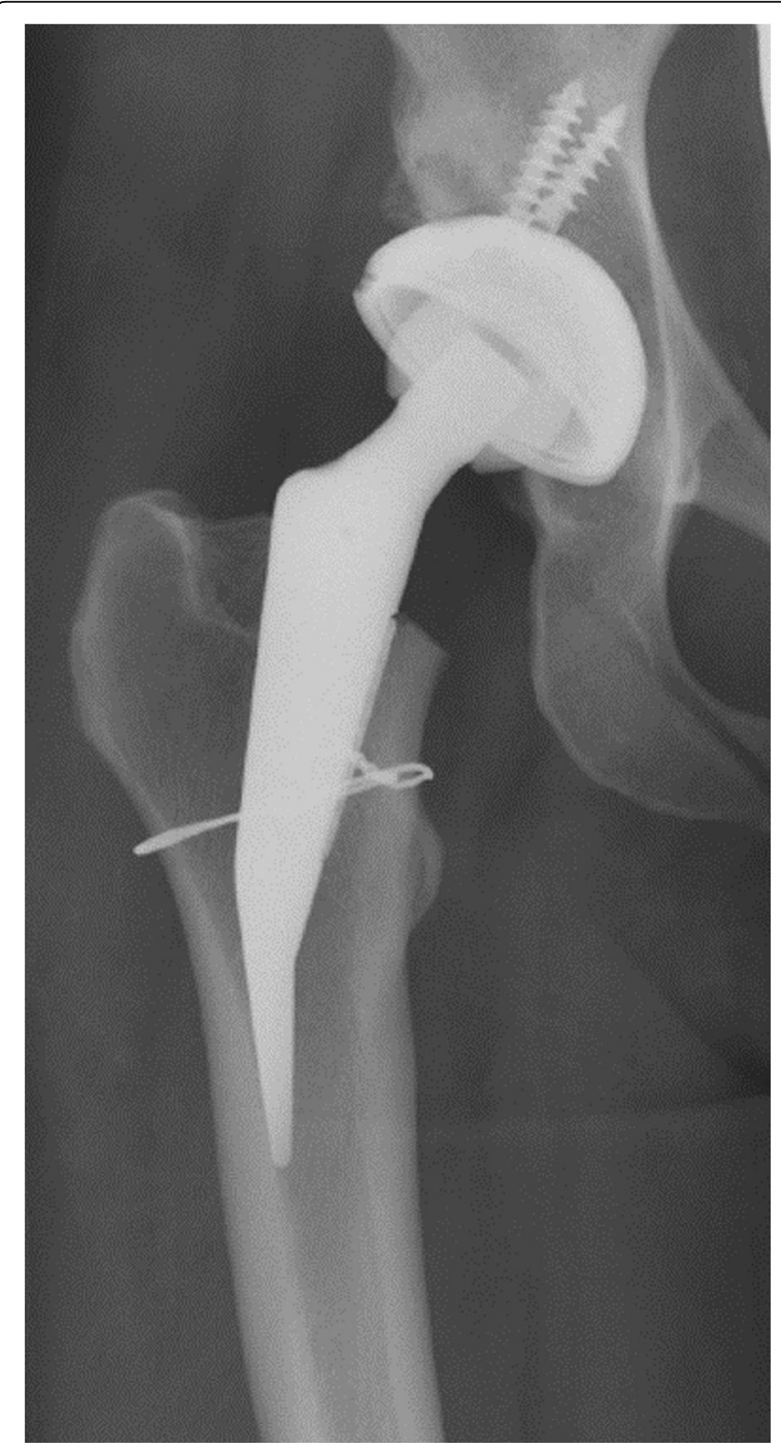

Fig. 4 Non displaced periprosthetic fracture of the proximal femur treated with a cerclage

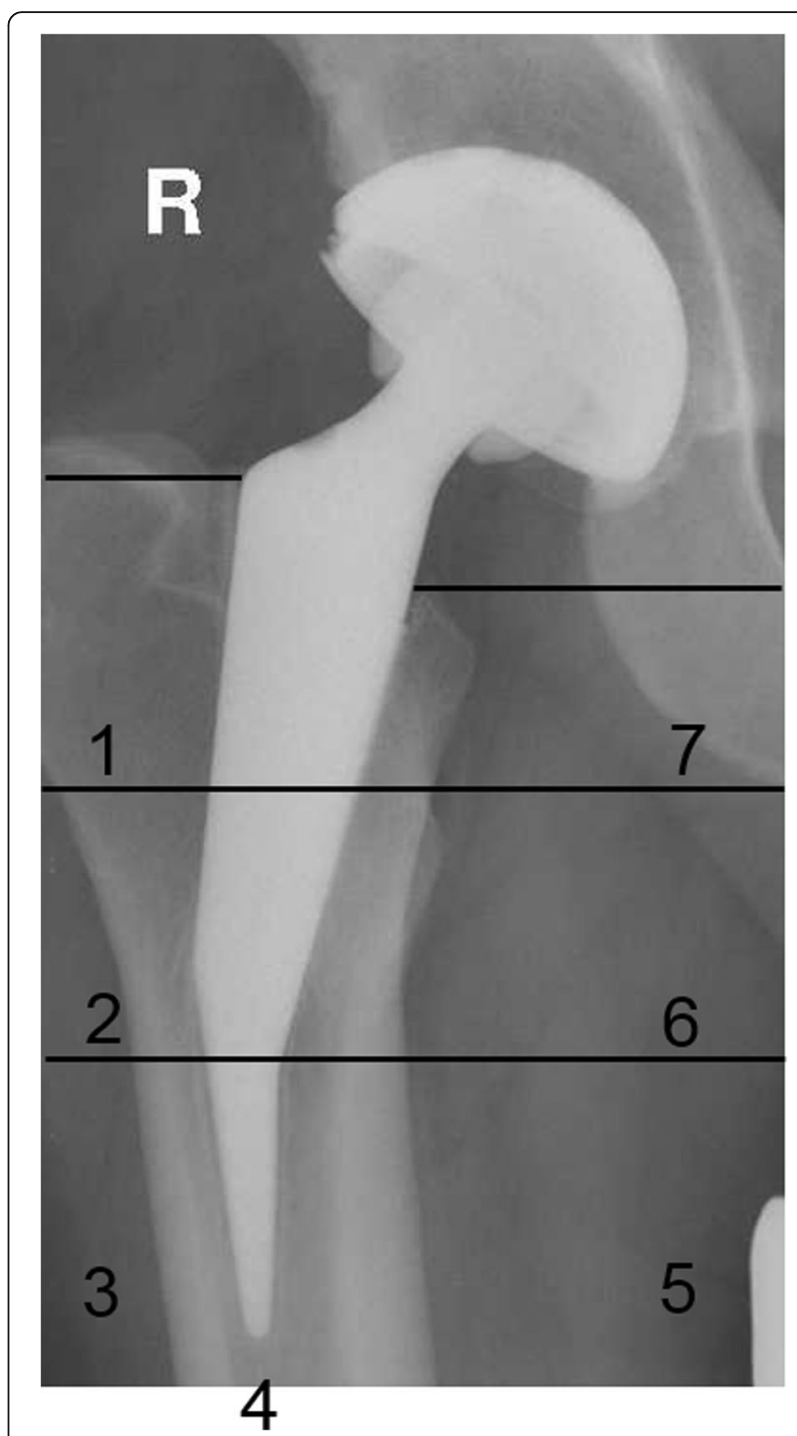

Fig. 5 Radiographic appearance of linear radiolucencies in the zones 1, 3 and 5 of Gruen

femoral fracture in the calcar region in $12.1 \%$ of the cases. Morrey et al. [1] reported a frequency of $7 \%$ whereas studies by Hube et al. [5] and Falez et al. [6] reported a frequency of 2.2 and $2.5 \%$, respectively.

The higher complication rate in our group can be attributed to the surgeons' learning curves. The more obese patient cohort in our study compared to previously reported outcome analyses may be another reason

Table 3 Comparison of preoperative and postoperative lateral offset, leg length and CCD angle

\begin{tabular}{llll}
\hline & Preoperative & Postoperative & change \\
\hline Lateral offset $[\mathrm{mm}]$ & $43.1( \pm 7.0)$ & $46.3( \pm 16.5)$ & $3.9( \pm 18.5)$ \\
leg length $[\mathrm{mm}]$ & $-2.1( \pm 9.9)$ & $2.3( \pm 11.3)$ & $4.3( \pm 12.8)$ \\
CCD angle & $134.7^{\circ}\left( \pm 6.4^{\circ}\right)$ & $132.8^{\circ}( \pm 16.9)$ & $-2.3^{\wedge}( \pm 18.0)$ \\
\hline
\end{tabular}




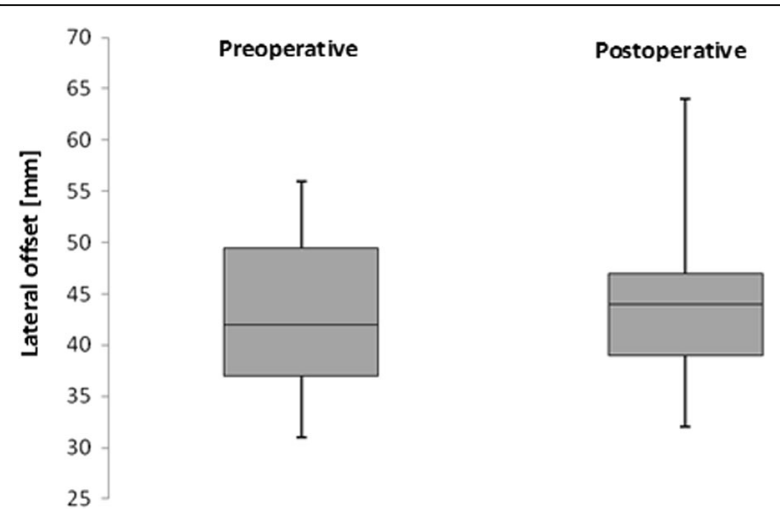

Fig. 6 There was no significant change in the pre- and postoperative lateral offset after total hip replacement using the mayo conservative hip

for the relatively high complication rate. Due to acute late onset infection 13 months after implantation, one patient was treated by revision of the mobile implant parts in a one-step procedure. Other revisions were not necessary.

The Swedish hip arthroplasty registry [20] reported 5 year revision rates for patients under 60 years being $2 \%$ excluding interventions to replace acetabular components due to primary instabilities. Survival rates without revision of a femoral short-stem component and aseptic loosening have been reported as 98\% after 6.8 years in 162 treatments [1], 99\% in 155 cases after 6.2 years [21], 100\% after 5.2 years [22] and 95, 2\% in the current study.

The fractures of this study occurred during stem insertion. In that case, the stem was removed, cerclage-wires were placed around the minor trochanter of the femur and re-insertion of the stem was performed (Fig.4). Afterwards, patients were treated without weight bearing for 3 or 6 weeks, and after this $20 \mathrm{~kg}$ partial weight bearing before transition to full weight bearing. Another recent study showed that patients treated similarly to

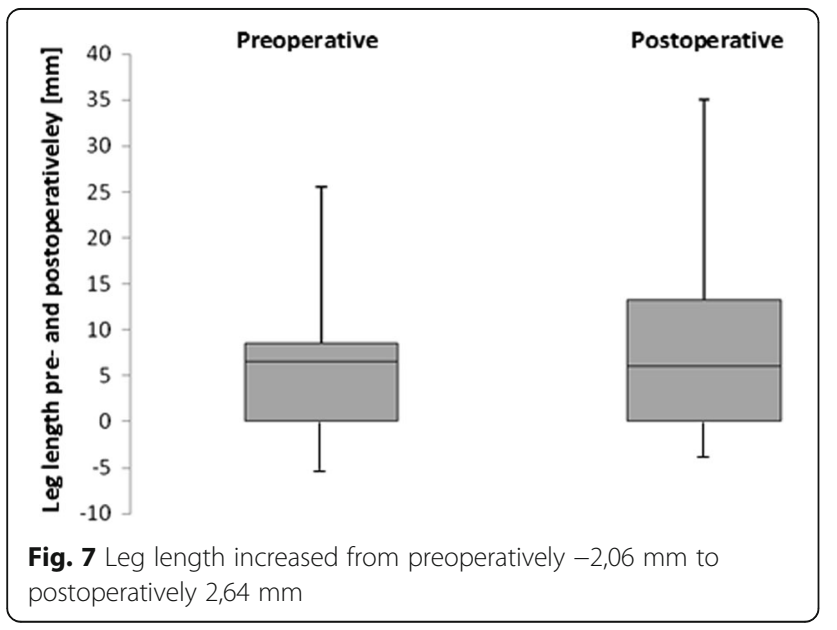

ours after intraoperative fracture using a mayo short stem prosthesis, had no disadvantages referring stem migration or alignment [23].

We assumed that the fractures occurred due to high radial tension evolving in the lumen of the femur during stem insertion [24]. Previous studies [9, 10, 22, 24] found that the fissures have mostly been located at the point where the cortex is thinnest and therefore most vulnerable, as it was in the current study. The fractures are almost always found to be parallel to the metaphyseal axis. Moreover, they have been found to be usually not detectable in conventional radiographic imaging [24]. This is due to the fact that longitudinal fractures often coincide with the projection of the stem.

Fractures that are located medially remain often clinically undetected and the implant is therefore not sufficiently fixed. Within this context, diminished bone density has been described as predisposing factor for periprosthetic fractures $[6,24,25]$. Another study including a low number of patients treated with the mayo stem also showed increased numbers of intraoperative fractures (13.3\%) with 2 cases in 15 patients [26]. In the present study, diabetes, higher body mass index and older ages are shown to be risk factors for intraoperative periprosthetic fracture $(p<0.01)$.

Good functional results and good short-term and midterm survival rates have been reported for various shortstem hip designs $[6,10,19,27]$. An advantage of SHA is the potential preservation of the femoral bone stock making it possible to use of a conventional stem if a revision should become necessary, thus avoiding revision implants [6, 24]. Furthermore, advantages of SHA include a reduced soft-tissue trauma and a more physiological load transfer at the metaphyseal part of the femur. The curved small stem designs facilitate the preparation and the insertion of the stem [6] resulting in reduced hospital length of stay and a faster post-operative mobilisation [24].

In summary, literature is conflicting with overall cumulative failure rates between 0.9 and 5.7\% [28], which is in line with the results of this study with a failure rate of $4.8 \%$. Overall, SHA offers a sufficient alternative, especially for younger patients requiring hip replacement. However, surgeons should be aware of potential risk factors such as diabetes mellitus and/or obesity, especially when they start to use the described short stem system.

\section{Conclusion}

In this cohort, THA with the Mayo conservative hip shows acceptable mid-term results with an improvement of the HHS from 61.2 to 85.6. A higher complication rate compared to conventional cementless designs was observed, with a high rate of non-displaced proximal femoral fractures. This could be attributed to the 
surgeon's learning curve, the stem design and patient inherent risk factors such as diabetes mellitus and/or obesity. Therefore surgeons using this implant should be aware of the inherent flat learning curve of the system and be particularly careful in their patient selection. Intraoperative fluoroscopic imaging is highly recommendedto detect periprosthetic femoral fissures.

\section{Limitations}

Only short-term and mid-term results are available for SHA and these results still have to be confirmed by long-term studies and larger patient cohorts with a focus on risk factors.

\section{Abbreviations}

AP: Anterior-posterior; BMI: Body mass index; DAA: Direct anterior approach; HHS: Harris Hip Score; MIS: Minimal invasive surgery; OA: Osteoarthritis; SMFA: Short Musculoskeletal Function Assessment Questionnaire; THA: Tota hip arthroplasty; XSFMA-D: German Extra Short Musculoskeletal Function Assessment Questionnaire

\section{Acknowledgements}

None.

\section{Funding}

This publication was supported by the Open Access Publication Fund of the University of Wuerzburg.

\section{Availability of data and materials}

All data can be requested at j-arnholdt.klh@uni-wuerzburg.de. All data supporting the findings of this study can be found in additional supporting files.

\section{Authors' contributions}

JA was responsible for the design and coordination of this study and wrote the manuscript. FG and MB were responsible for the acquisition of data, interpretation of data and performed the statistical analysis. JP was significantly involved in data analysis. UN and MR supervised the project and helped to draft the manuscript. AFS revised the manuscript and gave his final approval for publication. All authors read and approved the final manuscript.

\section{Competing interests}

The authors declare that they have no conflict of interest

\section{Consent for publication}

Not applicable.

\section{Ethics approval and consent to participate}

This study was performed at the Department of Orthopaedic Surgery, University of Wuerzburg, Wuerzburg, Germany and approved by the ethical committee University of Wuerzburg, Germany with the approval number 2016020501, on 29th February 2016 application date 5th February 2016.

\section{Publisher's Note}

Springer Nature remains neutral with regard to jurisdictional claims in published maps and institutional affiliations.

\section{Author details}

'Department of Orthopaedic Surgery, König-Ludwig-Haus, Julius-Maximilians-University, Brettreichstr. 11, 97074 Würzburg, Germany. 2Department of Trauma, Hand, Plastic and Reconstructive Surgery, University Hospital Wuerzburg, Oberduerrbacher Str. 6, 97080 Würzburg, Germany. ${ }^{3}$ Department of Orthopaedic Surgery and Traumatology, Evangelisches Waldkrankenhaus Spandau, Stadtrandstraße 555, 13589 Berlin, Germany. ${ }^{4}$ Department of Trauma and Orthopaedic Surgery, Agatharied Hospital, Norbert-Kerkel-Platz, 83734 Hausham, Germany.
Received: 14 February 2017 Accepted: 2 June 2017

Published online: 09 June 2017

\section{Reference}

1. Morrey BF, Adams RA, Kessler M. A conservative femoral replacement for total hip arthroplasty. A prospective study. J Bone Joint Surg. 2000; 82(7):952-8.

2. Morrey BF. Short-stemmed uncemented femoral component for primary hip arthroplasty. Clin Orthop Relat Res. 1989:249:169-75.

3. Goebel D, Schultz W. The Mayo cementless femoral component in active patients with osteoarthritis. Hip Int. 2009;19(3):206-10.

4. Learmonth ID, Young C, Rorabeck C. The operation of the century: total hip replacement. Lancet. 2007:370(9597):1508-19.

5. Hube R, Zaage M, Hein W. Reichel H: [early functional results with the Mayo-hip, a short stem system with metaphyseal-intertrochanteric fixation]. Der Orthopade. 2004;33(11):1249-58.

6. Falez F, Casella F, Panegrossi G, Favetti F, Barresi C. Perspectives on metaphyseal conservative stems. Ital J Orthop Traumatol. 2008;9(1):49-54.

7. van Gerwen M, Shaerf DA, Veen RM. Hip resurfacing arthroplasty. Acta Orthop. 2010:81(6):680-3.

8. Toth K, Mecs L, Kellermann P. Early experience with the Depuy Proxima short stem in total hip arthroplasty. Acta Orthop Belg. 2010;76(5):613-8.

9. Gotze C, Ehrenbrink J. Ehrenbrink H: [is there a bone-preserving bone remodelling in short-stem prosthesis? DEXA analysis with the Nanos total hip arthroplasty]. Zeitschrift fur Orthopadie und Unfallchirurgie. 2010:148(4):398-405

10. Broeke RH, Harings SE, Emans PJ, Jutten LM, Kessels AG, Geesink RG. Randomized comparison between the cemented scientific hip prosthesis and Omnifit: 2-year DEXA and minimum 10-year clinical follow-up. J Arthroplast. 2013;28(8):1354-61.

11. Banerjee S, Pivec R, Issa K, Harwin SF, Mont MA, Khanuja HS. Outcomes of short stems in total hip arthroplasty. Orthopedics. 2013;36(9):700-7.

12. Goebel S, Steinert AF, Schillinger J, Eulert J, Broscheit J, Rudert M, et al. Reduced postoperative pain in total hip arthroplasty after minimal-invasive anterior approach. Int Orthop. 2012;36(3):491-8.

13. Reichert JC, Volkmann MR, Koppmair M, Rackwitz L, Ludemann M, Rudert $\mathrm{M}$, et al. Comparative retrospective study of the direct anterior and transgluteal approaches for primary total hip arthroplasty. Int Orthop. 2015:39(12):2309-13.

14. Rudert M, Horas K, Hoberg M, Steinert A, Holzapfel DE, Hubner S, et al. The Wuerzburg procedure: the tensor fasciae latae perforator is a reliable anatomical landmark to clearly identify the Hueter interval when using the minimally-invasive direct anterior approach to the hip joint. BMC Musculoskelet Disord. 2016:17:57.

15. Noth U, Nedopil A, Holzapfel BM, Koppmair M, Rolf O, Goebel S, et al. Rudert M: [minimally invasive anterior approach]. Der Orthopade. 2012; 41(5):390-8

16. Wollmerstedt $\mathrm{N}$, Faller $\mathrm{H}$, Ackermann $\mathrm{H}$, Schneider J, Glatzel M, Kirschner S, et al. Evaluation of the Extra short musculoskeletal function assessment questionnaire XSMFA-D in patients with musculoskeletal disorders and surgical or medical in-patient treatment. Die Rehabilitation. 2006;45(2):78-87.

17. Swiontkowski MF, Engelberg R, Martin DP, Agel J. Short musculoskeletal function assessment questionnaire: validity, reliability, and responsiveness. J Bone Joint Surg Am. 1999:81(9):1245-60.

18. Chen HH, Morrey BF, An KN, Luo ZP. Bone remodeling characteristics of a short-stemmed total hip replacement. J Arthroplast. 2009;24(6):945-50.

19. Australian orthopaedic association national joint replacement registry annual report. 2011. [http://www.surfacehippy.info/pdf/australian-nat-reg-2011.pdf].

20. Swedish hip arthroplasty register, annual report. 2010. [https://registercentrum. blob.core.windows.net/shpr/r/Annual-report-2010-Hy_wFlaox.pdf].

21. Briem D, Schneider M, Bogner N, Botha N, Gebauer M, Gehrke T, et al. Midterm results of 155 patients treated with a collum femoris preserving (CFP) short stem prosthesis. Int Orthop. 2011;35(5):655-60.

22. Ettinger $M$, Ettinger $P$, Lerch $M$, Radtke $K$, Budde $S$, Ezechieli $M$, et al. The NANOS short stem in total hip arthroplasty: a mid term follow-up. Hip Int 2011;21(5):583-6.

23. Zeh A, Radetzki F, Diers V, Bach D, Rollinghoff M, Delank KS. Is there an increased stem migration or compromised osteointegration of the Mayo short-stemmed prosthesis following cerclage wiring of an intrasurgical periprosthetic fracture? Arch Orthop Trauma Surg. 2011;131(12):1717-22. 
24. Richards CJ, Duncan CP, Masri BA, Garbuz DS. Femoral revision hip arthroplasty: a comparison of two stem designs. Clin Orthop Relat Res. 2010; 468(2):491-6.

25. Tahim AS, Stokes OM, Vedi V. The effect of femoral stem length on duration of hospital stay. Hip Int. 2012;22(1):56-61.

26. Suksathien Y, Narkbunnam R, Sueajui J. Initial clinical and radiographic results with the short stem THA. J Med Assoc Thai= Chotmaihet thangphaet. 2012;95(Suppl 10):S26-31.

27. Zeh A, Weise A, Vasarhelyi A, Bach AG, Wohlrab D. Medium-term results of the Mayo short-stem hip prosthesis after avascular necrosis of the femoral head. Zeitschrift fur Orthopadie und Unfallchirurgie. 2011;149(2):200-5.

28. Molli RG, Lombardi AV Jr, Berend KR, Adams JB, Sneller MA. A short tapered stem reduces intraoperative complications in primary total hip arthroplasty. Clin Orthop Relat Res. 2012;470(2):450-61.

Submit your next manuscript to BioMed Central and we will help you at every step:

- We accept pre-submission inquiries

- Our selector tool helps you to find the most relevant journal

- We provide round the clock customer support

- Convenient online submission

- Thorough peer review

- Inclusion in PubMed and all major indexing services

- Maximum visibility for your research

Submit your manuscript at www.biomedcentral.com/submit
Biomed Central 